\title{
An acute intake of plant stanol esters alters immune-related pathways in the jejunum of healthy volunteers
}

\author{
Els De Smet ${ }^{1}$, Ronald P. Mensink ${ }^{1}$, Mark V. Boekschoten ${ }^{2}$, Rogier de Ridder ${ }^{3}$, Wilfred T. V. Germeraad ${ }^{4}$, \\ Tim G. A. M. Wolfs ${ }^{5}$ and Jogchum Plat ${ }^{1 *}$ \\ ${ }^{1}$ Department of Human Biology, School for Nutrition, Toxicology and Metabolism (NUTRIM), Maastricht University \\ Medical Center, PO Box 616, NL-6200 MD Maastricht, The Netherlands \\ ${ }^{2}$ Nutrition, Metabolism and Genomics Group, Division of Human Nutrition, Wageningen University, Wageningen, \\ The Netherlands \\ ${ }^{3}$ Division of Gastroenterology and Hepatology, Department of Internal Medicine, Maastricht University Medical Center, \\ Maastricht, The Netherlands \\ ${ }^{4}$ Division of Hematology, Department of Internal Medicine, Maastricht University, Maastricht, The Netherlands \\ ${ }^{5}$ Department of Pediatrics, School of Oncology and Developmental Biology, Maastricht University Medical Center, \\ Maastricht, The Netherlands
}

(Submitted 21 May 2014 - Final revision received 19 September 2014 - Accepted 2 October 2014 - First published online 16 February 2015)

\begin{abstract}
Plant sterols and stanols inhibit intestinal cholesterol absorption and consequently lower serum LDL-cholesterol (LDL-C) concentrations. The underlying mechanisms are not yet known. In vitro and animal studies have suggested that changes in intestinal sterol metabolism are attributed to the LDL-C-lowering effects of plant stanol esters. However, similar studies in human subjects are lacking. Therefore, we examined the effects of an acute intake of plant stanol esters on gene expression profiles of the upper small intestine in healthy volunteers. In a double-blind cross-over design, fourteen healthy subjects (eight female and six male; age 21-55 years), with a BMI ranging from 21 to $29 \mathrm{~kg} / \mathrm{m}^{2}$, received in random order a shake with or without plant stanol esters $(4 \mathrm{~g})$. At $5 \mathrm{~h}$ after consumption of the shake, biopsies were taken from the duodenum (around the papilla of Vater) and from the jejunum $(20 \mathrm{~cm}$ distal from the papilla of Vater). Microarray analysis showed that the expression profiles of genes involved in sterol metabolism were not altered. Surprisingly, the pathways involved in T-cell functions were down-regulated in the jejunum. Furthermore, immunohistochemical analysis showed that the number of CD3 (cluster of differentiation number 3), CD4 (cluster of differentiation number 4) and Foxp $3^{+}$(forkhead box P3-positive) cells was reduced in the plant stanol ester condition compared with the control condition, which is in line with the microarray data. The physiological and functional consequences of the plant stanol ester-induced reduction of intestinal T-cell-based immune activity in healthy subjects deserve further investigation.
\end{abstract}

Key words: Immune function: Intestinal gene expression profiles: Microarray analysis: Plant stanol esters

Plant sterols in habitual diets are mainly derived from vegetable oils, nuts, grains, fruit and vegetables, and daily intakes vary from 160 to $360 \mathrm{mg}^{(1)}$. Avoiding the diet containing plant sterols slightly increases the concentrations of serum LDL-cholesterol $^{(2)}$. In contrast, increasing the daily intakes of plant sterols by 2 to $3 \mathrm{~g}$ using functional foods lowers the concentrations of serum LDL-cholesterol up to $10 \%{ }^{(3)}$. Despite these well-known effects of plant sterol intake on serum LDL-cholesterol levels, there is a lack of detailed understanding about the underlying mechanisms. In vitro and animal studies have suggested that plant sterols affect intestinal cholesterol metabolism at the cellular level ${ }^{(4)}$. There are multiple suggestions that plant sterols affect specific processes in the intestine. For example, Lee et al. ${ }^{(5)}$ demonstrated that $\beta$-sitosterol inhibited the shortening of the colon, lowered macroscopic scores of the disease grade and myeloperoxidase activity, and inhibited the release of pro-inflammatory cytokines in mice with 2,4,6-trinitrobenzene-induced colitis. In addition, $\beta$-sitosterol inhibited the growth of colon cancer cells in vitro, suggesting its chemopreventive effects against colon cancer ${ }^{(6)}$.

Abbreviations: CD3, cluster of differentiation number 3; CD4, cluster of differentiation number 4; Foxp3, forkhead box P3; LXR, liver X receptor; Th1, T helper 1 cells; Th2, T helper 2 cells; Treg, regulatory T cells.

*Corresponding author: Dr J. Plat, fax +31 433670976, email j.plat@maastrichtuniversity.nl 
Time (weeks) $\longrightarrow$

Plant sterol/stanol-poor diet

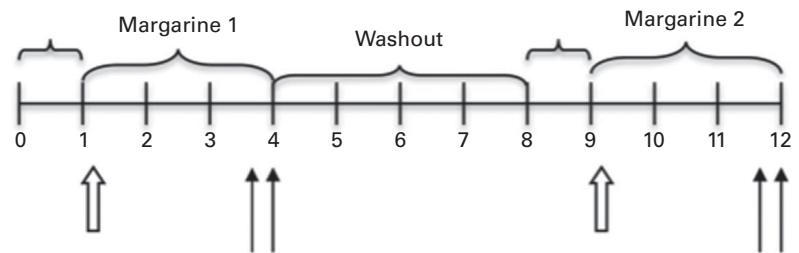

Fig. 1. Schematic overview of the study design. $\uparrow$, Blood sample; $\Uparrow$, postprandial test (intestinal biopsies were taken).

A study conducted in mice fed plant sterols for 2 weeks has shown increased faecal neutral sterol excretion associated with lipid metabolism, probably via the activation of the transintestinal cholesterol excretion pathway ${ }^{(7)}$. Field et al. ${ }^{(8)}$ further showed that mRNA expression levels of 3-hydroxy-3methylglutaryl-CoA reductase were decreased after incubating $\mathrm{Caco} 2$ cells with micelles containing $\beta$-sitosterol. Finally, it has been postulated that plant sterols and stanols could act as local liver X receptor (LXR) agonists in enterocytes ${ }^{(9)}$. However, despite all these interesting observations, data on the effects of plant sterol- or stanol-enriched food consumption on human enterocytes are lacking. Therefore, to better understand the cellular effects in the intestine, we examined the acute changes in the transcriptome of the upper small intestine in healthy individuals after consuming a plant stanol-enriched shake at breakfast after an overnight fast. Pathways involved in sterol metabolism were not altered in both the duodenum and the jejunum. However, immune-related pathways were down-regulated in the jejunum. This extends our earlier in vitro finding that sitostanol may exert immunomodulatory effects in subjects with a disturbed T-cell response ${ }^{(10)}$. However, the present study population had no known immune disorders. Therefore, the effects of plant stanol and sterol esters on the (intestinal) immune system deserve further attention.

\section{Materials and methods}

\section{Study design}

The present study was part of a previously published randomised double-blind cross-over trial ${ }^{(4)}$. In brief, a total of eighteen healthy normolipidaemic volunteers participated in two experimental periods of 4 weeks, separated by a 4 -week washout period (Fig. 1). Although intake of plant stanol esters is advised for (slightly) hypercholesterolaemic subjects, reductions and the underlying mechanisms in normolipidaemic subjects are comparable ${ }^{(11,12)}$. During two screening visits, which were separated by at least $3 \mathrm{~d}$, body weight, height and blood pressure of the participants were determined. An Omron M7 (Omron Healthcare Europe B.V.) was used to measure blood pressure in 4-fold in the left arm. The first measurement was discarded and the last three measurements were averaged. Since there are no studies so far that have shown an effect of BMI and sex on the cholesterol-lowering effects of plant stanol esters, men as well as women with a BMI ranging from 20 to $30 \mathrm{~kg} / \mathrm{m}^{2}$ were included.
Blood samples were taken for the analysis of serum total cholesterol concentrations. Subjects were excluded from analysis if their mean serum total cholesterol concentration was $>7.8 \mathrm{mmol} / \mathrm{l}$.

At 1 week before the start of each experimental period, subjects were instructed to avoid dietary products that were relatively rich in plant sterols and stanols. Immediately after this week, all subjects participated in a postprandial test for the examination of the acute effects of plant stanol esters on the expression profiles of intestinal genes. To further minimise the differences between two postprandial test days, all subjects consumed a standard lasagne meal at dinner, the evening before the test days. Except for water, they were not allowed to consume any other foods or drinks after dinner until the morning of the postprandial test. In the morning, they arrived at our department by public transportation or by car to reduce physical activity as much as possible. After resting for $15 \mathrm{~min}$ in a supine position, a fasting blood sample was collected (T0) by inserting an intravenous cannula into the antecubital vein. Next, subjects consumed a slice of white bread with jam and a high-fat shake with or without plant stanol esters ( $4 \mathrm{~g}$ plant stanols). The plant stanol ester mixture was incorporated into margarines as provided by Raisio (Raisio Nutrition Limited, Finland) and was composed of sitostanol (73.2\%), campestanol (22\%), sitosterol (0.9\%), campesterol (1.6\%) and other sterols/stanols (2.3\%). Plant stanols were esterified with food-grade fatty acids based on rapeseed oil. The margarine was incorporated into the shake (Table 1). Volunteers were requested to consume the shake and bread within $10 \mathrm{~min}$, and were not allowed to consume any other foods or drinks except water during the next $5 \mathrm{~h}$. At $5 \mathrm{~h}$ after consumption of the shake, intestinal biopsies were taken at the gastroenterology unit. During gastroscopy, no sedatives were given to the subjects. To compare the expression profiles of genes at different parts of the proximal small intestine, four mucosal tissue samples from the duodenum (around the papilla of Vater) and four from the jejunum $(20 \mathrm{~cm}$ distal from the papilla of Vater) were taken using standard biopsy forceps. The diameter of the biopsies varied from $2 \cdot 0$ to $2.2 \mathrm{~mm}$. After sampling, the biopsies were immediately frozen in liquid $\mathrm{N}_{2}$ for microarray analysis. For histological analysis, the biopsies were first put on a drop of Tissue-Tek in isopentane followed by freezing in liquid $\mathrm{N}_{2}$. All the samples were stored at $-80^{\circ} \mathrm{C}$ and analysed at the end of the study within the same run. The present study was

Table 1. Nutritional composition and ingredients of the shake

\begin{tabular}{lc}
\hline Energy & \\
$\quad$ kcal & 723 \\
$\quad$ kJ & 3025 \\
Protein $(g)$ & 11.5 \\
Carbohydrates $(g)$ & $59 \cdot 2$ \\
Total fat $(g)$ & $48 \cdot 9$ \\
SFA (g) & $20 \cdot 1$ \\
MUFA (g) & $18 \cdot 4$ \\
PUFA (g) & $7 \cdot 6$ \\
Cholesterol (mg) & $250 \cdot 2$ \\
Plant stanols $(g)$ & 0 or 4 \\
\hline
\end{tabular}


conducted according to the guidelines laid down in the Declaration of Helsinki, and all procedures involving human subjects were approved by the Medical Ethical Committee of the University Hospital Maastricht. All subjects gave written informed consent before their participation in the study. The trial was registered at ClinicalTrials.gov as NCT01574417.

\section{Blood sampling}

Blood was sampled in serum and NaF-containing vacutainer tubes (Becton Dickinson). To obtain serum, blood samples taken in serum tubes were allowed to clot for $30 \mathrm{~min}$ at $21^{\circ} \mathrm{C}$, followed by centrifugation at $1300 \mathrm{~g}$ for $15 \mathrm{~min}$ at $21^{\circ} \mathrm{C}$. The NaF-containing tubes were placed on ice directly after sampling and centrifuged at $1300 \mathrm{~g}$ for $15 \mathrm{~min}$ at $4{ }^{\circ} \mathrm{C}$ within $60 \mathrm{~min}$. Serum and plasma aliquots were directly snap-frozen in liquid $\mathrm{N}_{2}$ and stored at $-80^{\circ} \mathrm{C}$ until analysis. All samples obtained from each subject were analysed within the same analytical run.

\section{Lipids}

Concentrations of serum total cholesterol (CHOD-PAP method; Roche Diagnostics Systems, Hoffmann-La Roche) and TAG with correction for free glycerol (GPO-Trinder; Sigma Diagnostics) were determined enzymatically in fasting serum samples.

\section{Glucose, insulin and high-sensitivity C-reactive protein concentrations}

Plasma glucose (Roche Diagnostic Systems, Hoffmann-La Roche) concentrations were measured. Serum insulin concentrations were determined using a human insulinspecific RIA kit (Linco Research). High-sensitivity C-reactive protein concentration was determined by a highly sensitive immunoturbidimetric assay (Kamiya Biomedical Company).

\section{Microarray processing and data analysis}

Total RNA was extracted from frozen mucosal samples obtained from the duodenum or the jejunum using TRIzol reagent (Invitrogen), and purified on columns using the Qiagen RNeasy Micro Kit (Qiagen). Total RNA $(35 \mathrm{ng} / \mu \mathrm{l})$ was labelled by using Whole-Transcript Sense Target Assay and hybridised to human whole-genome Affymetrix Gene 1.1 ST arrays targeting 19682 unique genes (Affymetrix). Individual genes were defined as 'changed' when comparison of the normalised signal intensities showed a $P$ value $<0.05$ in a two-tailed paired intensity-based moderated $t$ statistic. Further functional data analysis was performed on the filtered dataset with gene set enrichment analysis, and on the differentially expressed genes with Ingenuity Pathway Analysis software.

\section{Immunohistochemical analysis}

Frozen intestinal biopsies were sectioned at $5 \mu \mathrm{m}$ and fixed in filtered, ice-cold acetone for $15 \mathrm{~min}$ at $4{ }^{\circ} \mathrm{C}$, as described previously $^{(13)}$. Briefly, endogenous peroxidase activity was blocked with $0.3 \% \mathrm{H}_{2} \mathrm{O}_{2}$ in methanol. After washing, slides were blocked with bovine serum albumin for $30 \mathrm{~min}$ at room temperature. Subsequently, the slides were incubated overnight at $4^{\circ} \mathrm{C}$ with appropriate primary antibodies, i.e. a polyclonal rabbit anti-human CD3 (cluster of differentiation number 3) antibody (1:1000, DAKO A0452; DAKO), a monoclonal mouse anti-human CD4 (cluster of differentiation number 4) antibody (1:50, Abcam ab846) or a monoclonal mouse anti-human Foxp3 (forkhead box P3) antibody (1:250, eBioscience 14-7979). After washing, the sections were incubated for $1 \mathrm{~h}$ at room temperature with the appropriate secondary antibody, i.e. a biotin-conjugated polyclonal swine anti-rabbit Ig (1:200, DAKO E0353; DAKO), a biotin-conjugated polyclonal goat anti-mouse Ig (1:200, DAKO E0433; DAKO) or a biotin-conjugated goat antimouse Ig (1:200, DAKO E0433; DAKO). Immunostaining was enhanced with the Vectastain ABC Peroxidase Elite kit (1:50, PK-6200; Vector Laboratories) followed by nickel sulphate-diaminobenzidine staining. The sections were counterstained with $0 \cdot 1 \%$ Nuclear Fast Red in 5\% aluminium sulphate for $2 \mathrm{~min}$ and dehydrated in ascending ethanol series. Images of the jejunal sections were acquired at $100 \times$ magnification using a Leica DM2000 microscope equipped with a Leica DFC295 digital camera (Leica Microsystems) and Leica Application Suite (LAS) software (Leica LAS version 3.7; Leica Microsystems). As these staining procedures are laborious, analyses were carried out only in three randomly chosen subjects.

\section{Results}

\section{Subject characteristics}

A total of eighteen healthy participants completed the study. Intestinal samples from four participants were excluded from the microarray analysis as their RNA integrity numbers were too low to expect a successful outcome. The baseline characteristics of the remaining fourteen subjects are presented in Table 2.

Table 2. Baseline characteristics of the fourteen study participants (Mean values and standard deviations)

\begin{tabular}{|c|c|c|c|}
\hline & Mean & & SD \\
\hline Age (years) & 32 & & 13 \\
\hline $\mathrm{BMI}\left(\mathrm{kg} / \mathrm{m}^{2}\right)$ & $23 \cdot 9$ & & $2 \cdot 8$ \\
\hline Serum total cholesterol $(\mathrm{mmol} / \mathrm{l})$ & $5 \cdot 2$ & & $1 \cdot 1$ \\
\hline Serum TAG (mmol/l) & $1 \cdot 1$ & & 0.4 \\
\hline Plasma glucose (mmol/l) & $5 \cdot 2$ & & 0.4 \\
\hline Serum insulin $(\mu \mathrm{U} / \mathrm{ml})^{\star}$ & $13 \cdot 4$ & & $5 \cdot 1$ \\
\hline Serum hs-CRP (mg/l) & 10 & & 12 \\
\hline Systolic blood pressure (mmHg) & 118 & & 12 \\
\hline Diastolic blood pressure (mmHg) & 79 & & 8 \\
\hline \multicolumn{4}{|l|}{$\operatorname{Sex}(n)$} \\
\hline Female & \multicolumn{3}{|c|}{8} \\
\hline Male & \multicolumn{3}{|c|}{6} \\
\hline
\end{tabular}

hs-CRP, high-sensitivity C-reactive protein.

* To convert insulin in $\mu \mathrm{U} / \mathrm{ml}$ to pmol/l, multiply by 6.945 . 
19682 genes on the array

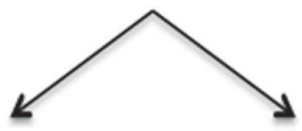

9852 genes in the duodenum

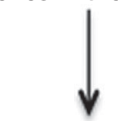

388 genes

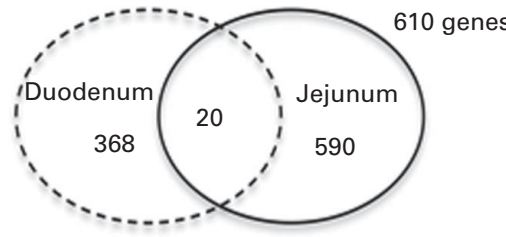

Fig. 2. Venn diagram showing the number of present and regulated genes determined by the microarray analysis of human intestinal biopsies. Probes were assigned to unique gene identifiers (Entrez). Genes were considered to be expressed when the intensity of the signal was $>20$ on at least eight arrays. Only genes with six or more probes were considered for the analysis. The $P$ value was $>0.05$ in a two-tailed paired intensity-based moderated $t$ statistic.

\section{Microarray analysis}

From the 19682 genes present in the microarray data, 9852 were expressed in the duodenum and 10003 in the jejunum. After consumption of a shake enriched with $4 \mathrm{~g}$ plant stanol esters, the expression of 388 genes in the duodenum and of 610 genes in the jejunum was significantly altered. However, the expression of only twenty genes was altered in both the duodenum and jejunum (Fig. 2).

\section{Gene set enrichment analysis}

At $5 \mathrm{~h}$ after consumption of plant stanol esters, expression profiles of genes present in the pathways involved in sterol metabolism were not found to be altered in biopsies taken from the duodenum or jejunum. Gene sets that were altered after consumption of plant stanol esters are presented in online Supplementary Table S1. A consistent finding in the jejunum was the down-regulation of gene sets in pathways such as T-cell receptor signalling, generation of second messenger molecules, phosphorylation of CD3 and T-cell receptor $\zeta$ chains, and downstream $\mathrm{T}$-cell receptor signalling (see online Supplementary Table S1). Part of the genes that were responsible for the observed enrichment in these gene sets were members of the CD family, which are all T-cellspecific surface molecules (Table 3). These effects were not observed in the samples obtained from the duodenum, in which modest changes appeared randomly.

\section{Ingenuity Pathway Analysis}

The immune-related functions that were affected by differentially regulated genes, as determined by gene set enrichment analysis, were also investigated (Fig. 3). A $z$ score above 2 or below -2 indicate, respectively, an increase or decrease in the specific function that was changed after consumption of plant stanol esters. An acute intake of plant stanol esters reduced the expression of genes associated with the quantity of double-positive thymocytes, as well as with the interaction, activation, adhesion and chemoattraction of $\mathrm{T}$ lymphocytes.

Fig. 4 displays heat maps of the gene sets that were associated with either the quantity (Fig. 4(a)) or the functionality (Fig. 4(b)) of $\mathrm{T}$ cells, which were regulated after consumption of plant stanol esters according to the Ingenuity Pathway Analysis software. A description of these genes can be found in Supplementary Table S2. These maps showed a highly consistent decrease in the transcript abundance level of genes associated with T-cell immune responses. However, for one of the subjects, the results were found to be highly aberrant, for which we have no explanation.

\section{Immunohistochemical analysis}

To further examine the consistent changes in the expression signatures of genes associated with the presence of $\mathrm{T}$ cells in the biopsies from the jejunum, the number of $\mathrm{CD}^{+}$cells in the jejunum of three randomly chosen subjects consuming the control and plant stanol-enriched shakes were quantified. CD3 is a T-cell-specific surface glycoprotein. As shown in Fig. 4, the number of $\mathrm{CD}^{+}$cells was reduced in the plant stanol ester condition when compared with the control condition. The microarray analysis also showed a decrease in the mRNA expression of $\mathrm{T}$ helper lymphocytes and regulatory $\mathrm{T}$ cells (Treg). Therefore, expression of CD4 and Foxp3 were analysed by immunohistochemistry in the biopsies. CD4 is a glycoprotein, among others, found on the surface of T helper cells, and Foxp3 is expressed especially in the $\mathrm{CD}^{+}$subpopulation of Treg. Compared with the control condition, the number of $\mathrm{CD}^{+}$and $\mathrm{Foxp}^{+}$cells was reduced in the plant stanol ester condition, which further extends support to the microarray data (Fig. 5).

\section{Discussion}

Numerous in vitro and animal studies have demonstrated the effects of plant sterols and stanols on intestinal function ${ }^{(14-18)}$, but there are no human data. Therefore, we evaluated the acute effects of plant stanol esters on the expression profiles of genes in biopsies from the human duodenum and jejunum

Table 3. Changes in cluster of differentiation (CD) genes in the jejunum after an acute intake of plant stanol esters

\begin{tabular}{lcc}
\hline Genes & Fold change & $P$ \\
\hline$C D 160$ & -1.19 & 0.05 \\
$C D 2$ & -1.14 & 0.04 \\
$C D 27$ & -1.18 & 0.04 \\
$C D 3 D$ & -1.18 & 0.03 \\
$C D 3 G$ & -1.30 & 0.02 \\
CD4 & -1.20 & 0.02 \\
CD52 & -1.14 & 0.01 \\
CD59 & 1.09 & 0.04 \\
CD84 & -1.15 & 0.03 \\
CD97 & -1.16 & $<0.01$ \\
\hline
\end{tabular}




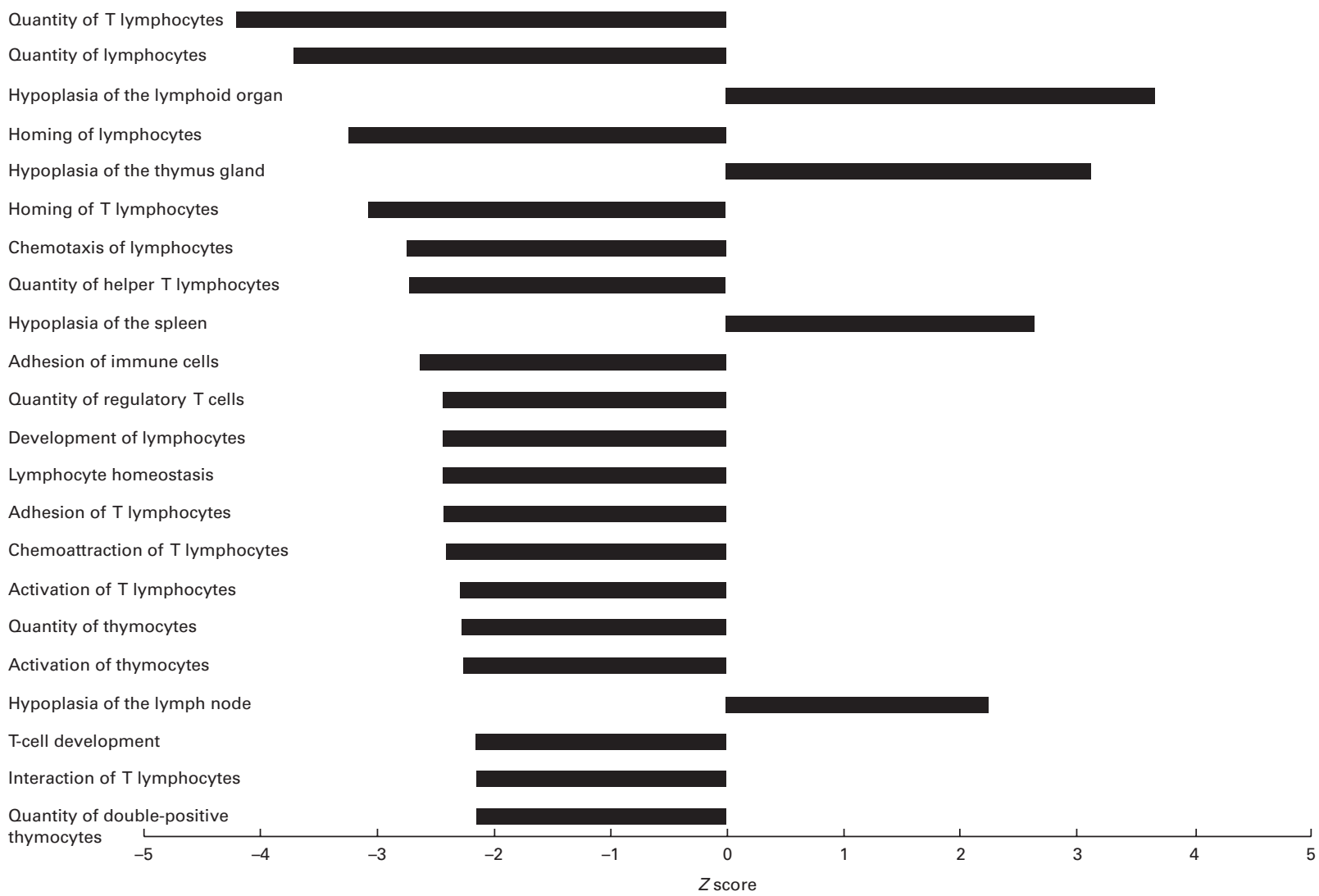

Fig. 3. Analysis of immune-related functions using the Ingenuity Pathway Analysis software in the jejunum after an acute intake of plant stanol esters. A $z$ score above 2 or below -2 indicates, respectively, an increase or decrease in the specific function that was significantly changed after consumption of plant stanol esters.

using microarray analysis. In contrast to our expectations, the expression profiles of genes involved in sterol metabolism were not altered. However, immune-related T-cell-oriented pathways were consistently down-regulated in the jejunum. The expression of villin 1-like protein, an enterocyte-specific actin-regulatory protein involved in the formation of microvilli in enterocytes ${ }^{(19)}$, was comparable between two test days (data not shown). This suggests that the number of enterocytes present in biopsies during the control and plant stanol ester conditions was comparable. The finding that T-cell-related pathways are not predominantly expressed in enterocytes suggests that at least part of the observed downregulation of T-cell-related pathways is due to the observed reduction in the number of $\mathrm{T}$ cells in the intestinal biopsies.

Knowledge regarding the intestinal kinetics of plant sterols and stanols and their effects on (intestinal) metabolism has rapidly evolved over the past decade. Recently, it was assumed that plant sterols and stanols are inert molecules and hardly absorbed, as their serum concentrations are low. However, it is now well established that concentrations of plant sterols and stanols in enterocytes can be increased up to 7 -fold ${ }^{(20)}$ without any significant changes in plasma concentrations. This can be explained by the presence of different sterol transporters in the apical membrane of enterocytes $^{(21-23)}$ that regulate the uptake and secretion of plant sterols. Intracellular concentrations of plant sterols and stanols can even reach the levels well above the half maximal effective concentration $\left(\mathrm{EC}_{50}\right)$ for specific transcription factors ${ }^{(17)}$. This suggests that plant sterols and stanols might affect gene regulation and modify metabolic pathways in vivo.

It has been reported that plasma concentrations of TAG increase within $120 \mathrm{~min}$ after food intake ${ }^{(24)}$. Thus, dietary lipids enter the enterocytes well before $2 \mathrm{~h}$. Therefore, we reasoned that a $5 \mathrm{~h}$ period was long enough to induce changes in gene expression. We further assumed that an acute challenge, when no new steady state was reached, was more powerful to induce changes in gene expression than challenging after a long-term intake. To minimise the effects of resident plant sterols on intestinal sterol metabolism during both test days and to create a contrast in plant sterol and stanol intake as large as possible, subjects were instructed to avoid the consumption of products relatively high in plant sterols and stanols 1 week before the test day. Yet, we could not exclude the fact that with another protocol with other time points or by measuring in steady-state conditions, changes in genes associated with lipid sterol metabolism could have been observed.

However, it is unlikely that this can be explained by a lack of absorption within the $5 \mathrm{~h}$ time frame of the study. Igel et $_{\text {al. }}{ }^{(20)}$ already showed an increase in plant sterol concentrations after $15 \mathrm{~min}$ in the enterocytes of male C57BL/ 6 OlaHsd mice. In agreement with this finding, we found an increase in plant stanol concentrations in the scraped enterocytes of $\mathrm{C} 57 \mathrm{Bl} / 6 \mathrm{~J}$ mice $15 \mathrm{~min}$ after an oral administration 


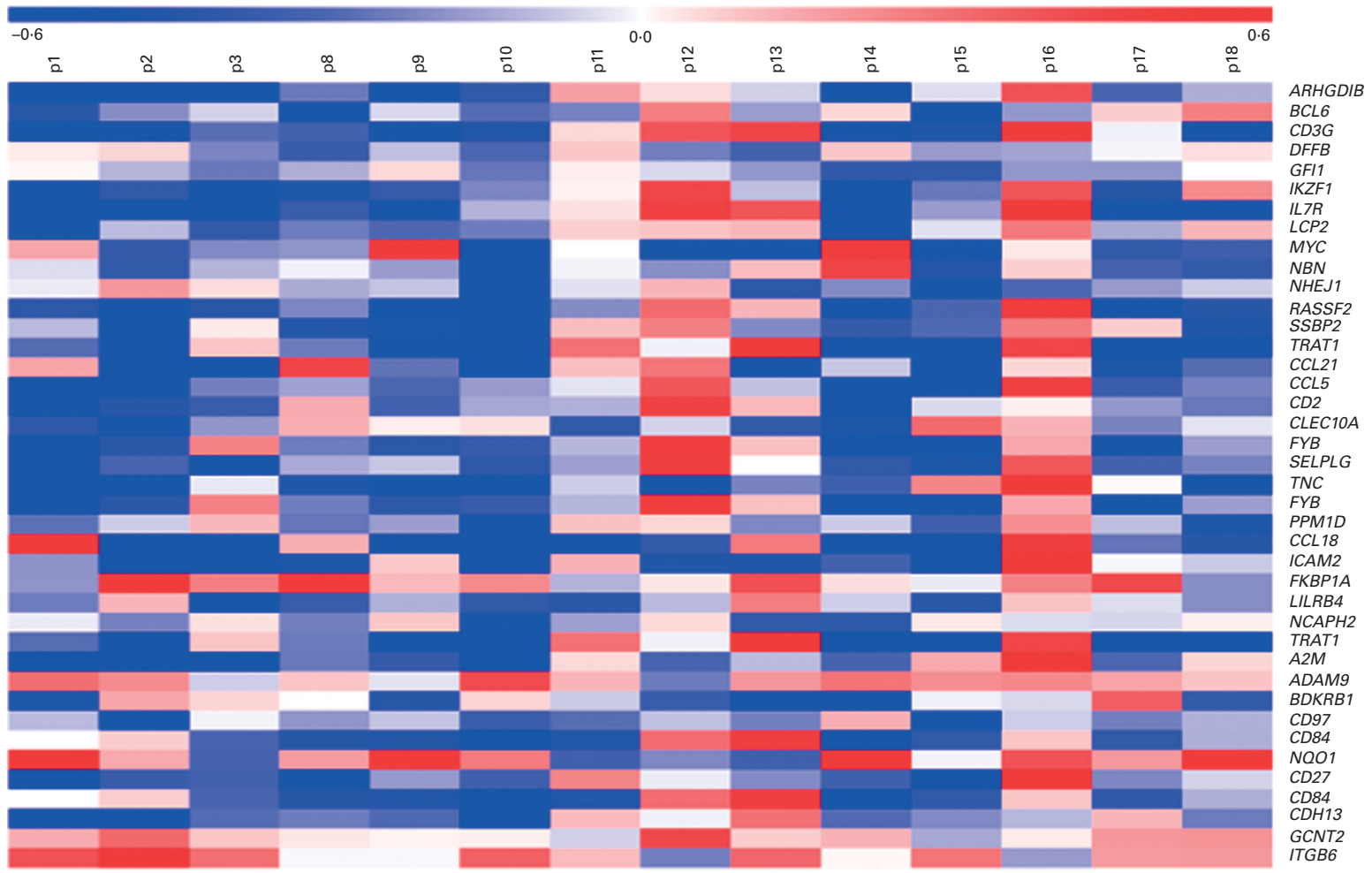

(b)

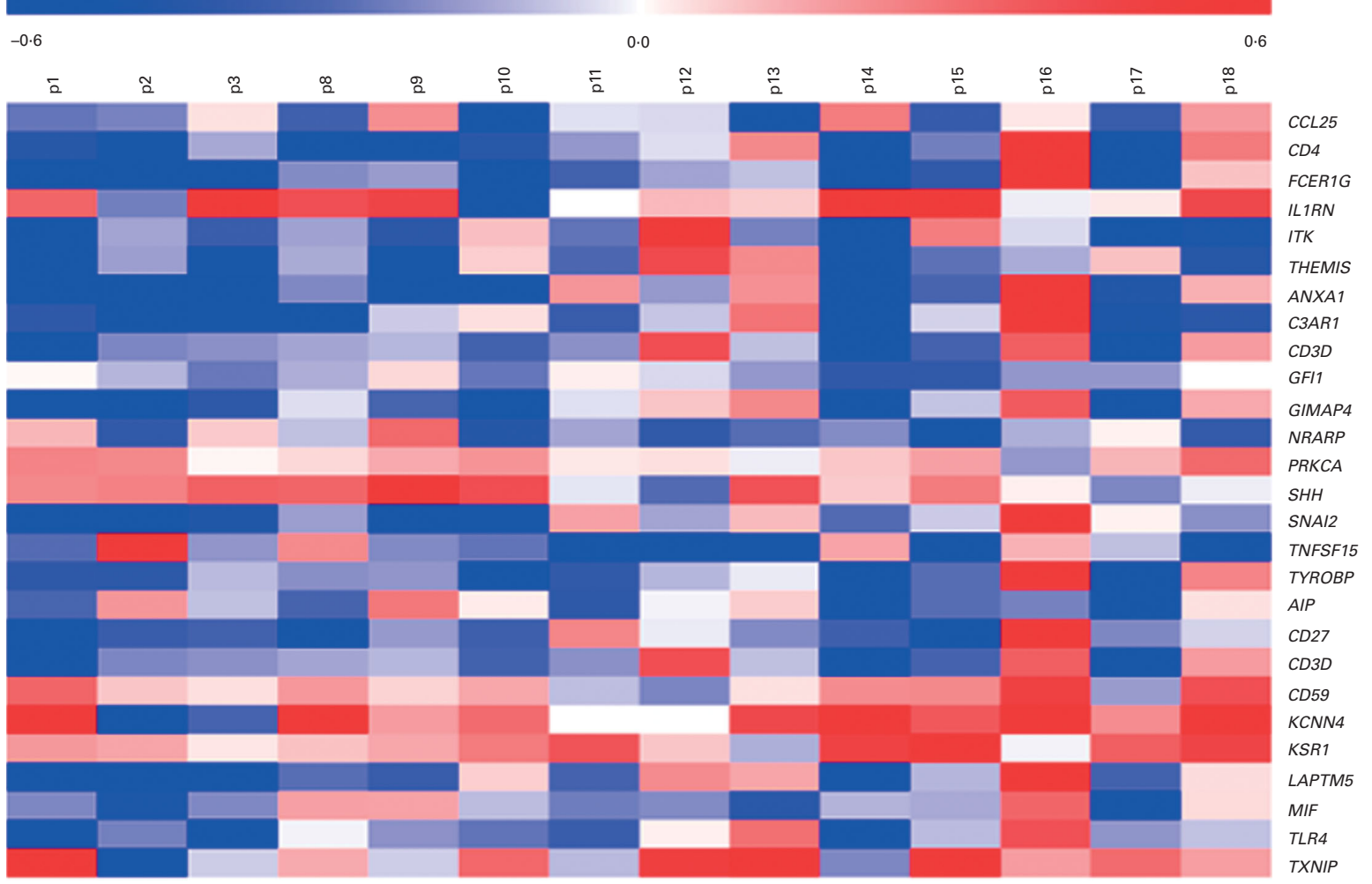

Fig. 4. Gene sets that were down-regulated in the jejunum after consumption of plant stanol esters, as determined by the Ingenuity Pathway Analysis software. The $z$ score was calculated by subtracting the mean expression value of each transcript from each of the values and then dividing the resulting values by the standard deviation. The colour displayed in the heat maps reflects the relative transcript abundance level of genes, with blue being lower and red higher than the mean transcript abundance value. Immune-related functions were classified into functions associated with (a) the quantity or (b) the functionality of $\mathrm{T}$ cells. Subject 1 is denoted by $\mathrm{p} 1$, subject 2 by $\mathrm{p} 2$, etc. For definition of gene names, see Supplementary Table S2. 


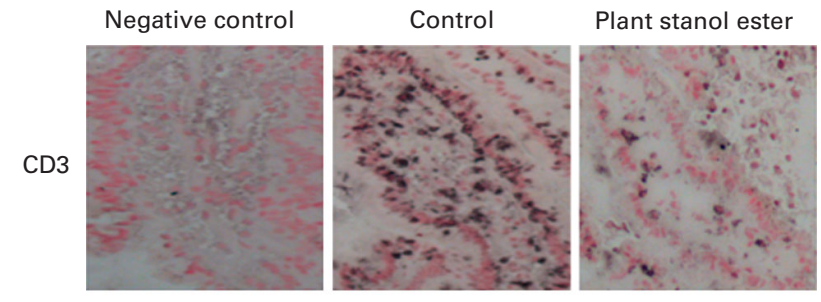

CD4

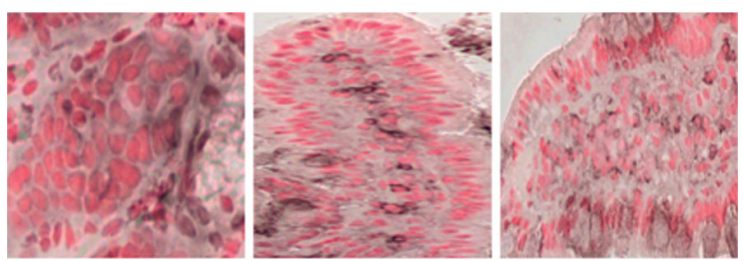

Foxp3
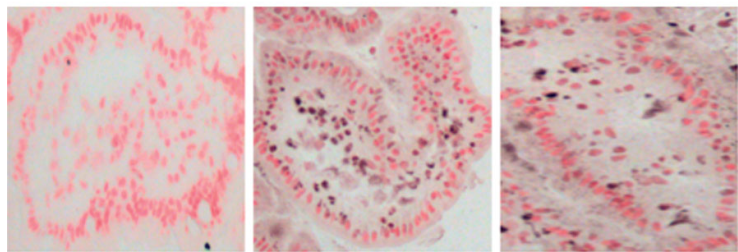

Fig. 5. Immunohistochemical analysis of CD3 (cluster of differentiation number 3), CD4 (cluster of differentiation number 4) and Foxp3 (forkhead box $\mathrm{P} 3$ ) in human jejunal biopsies $5 \mathrm{~h}$ after consumption of a shake enriched with or without plant stanol esters. Compared with the control condition, the number of CD3, CD4 and Foxp3 cells was reduced in the plant stanol ester condition.

(E De Smet, RP Mensink, M Konings, G Brufau, AK Groen, R Havinga, M Schonewille, A Kerksiek, D Lütjohann and J Plat, unpublished results). Also, in the present set-up, expression profiles of genes changed within $5 \mathrm{~h}$ after consumption of plant stanol esters. It might be possible that a $5 \mathrm{~h}$ follow-up period was too short to observe changes in the expression profiles of genes involved in sterol metabolism.

In animal studies, gene regulation in the intestine was observed within $12 \mathrm{~h}$ after the administration of a phytosterolderived LXR agonist $\left(\right.$ YT-32) ${ }^{(25)}$. No measurements were taken before this time point. A limited number of studies have also shown that in human subjects, expression profiles of intestinal genes involved in sterol metabolism can be changed during the postprandial phase ${ }^{(26,27)}$. The expression profiles of genes involved in the adaptive $\mathrm{T}$-cell immune response were down-regulated. We have already suggested that plant sterols and stanols influence immune function, when the immune response is disturbed. Brüll et al. ${ }^{(10)}$ showed that plant stanols induced a shift towards T helper 1 cells (Th1) in isolated human peripheral blood mononuclear cells from asthma patients. Furthermore, the number of Treg cells, which are important for maintaining the Th1/Th2 (T helper 2 cell) balance, tended to increase, whereas the activity of Treg cells increased significantly. These ex vivo changes may be specific for a situation of skewed T-cell behaviour, as they were not observed in peripheral blood mononuclear cells from healthy subjects characterised by a balanced Th1/Th2 response ${ }^{(10)}$. In vivo, Calpe-Berdiel et al. ${ }^{(28)}$ showed that administration of $2 \%$ phytosterols increased the Th1:Th2 ratio in mice treated with turpentine in order to induce an acute, aseptic inflammation model. The studies described so far have suggested that the plant stanol/sterol-induced Th1 or Th2 response depends on the direction of the disturbed Th1/Th2 balance. Restoration of this imbalance is probably the result of alterations in the number and activity of Treg cells ${ }^{(10)}$. In other words, when Th2 cells are overactivated, the activation of Treg cells restores the balance by stimulating the activity of Th1 cells, which via feedback mechanisms results in the dampening of Th2 cells ${ }^{(29)}$. However, in the present study, the changes in expression profiles suggested a dampening of the intestinal T-cell-mediated immune potential, in general, in healthy volunteers without an a priori skewed response. The physiological and functional consequences of these effects remain to be elucidated.

An intriguing question is how these effects on T cells can be explained. One may speculate that plant stanol esters induce changes in the composition of the gut microbiota, which may be associated with immunological processes ${ }^{(30)}$. Recently, Martinez et $a l .{ }^{(31)}$ showed that the faecal microbiota of hamsters was significantly altered after feeding a plant sterol-enriched diet for 4 weeks. However, it is not very likely that the gut microbiota has changed within the $5 \mathrm{~h}$ time frame of the present study. Another explanation is based on the observations of Bensinger et $a l^{(32)}$, who showed that the transcriptional regulation of intracellular cholesterol homeostasis is linked to cell proliferation and acquired immune responses. Ligand activation of LXR, thereby increasing the expression of ABCG1 (ATP-binding cassette transporter G1), prevented effective proliferative responses. In contrast, activation of $\mathrm{T}$ cells by an antigen was accompanied by an up-regulation of the SREBP pathway, resulting in an increased availability of sterols needed for membrane biogenesis. Furthermore, the activities of the oxysterol-metabolising enzyme sulfotransferase family cytosolic 2B member 1 (SULT2B1) and multi-drug resistance protein 1 (MRP1/ABCC1) were increased, thereby eliminating oxysterol ligands of LXR and leading to T-cell expansion ${ }^{(32,33)}$. Based on these findings, it can be speculated that plant stanols reduced the cellular oxycholesterol content of intestinal $\mathrm{T}$ cells, mimicking the effect of LXR activation and resulting in the dampening of T-cell expansion. However, further research is needed to elucidate this possible association. Unfortunately, the amount of biopsy material that we collected was too small to analyse the levels of oxysterol. In this context, it is interesting to investigate whether the effects observed are specific to plant stanols or whether similar effects could have been achieved by changing the dietary intake of cholesterol. In our earlier in vitro ${ }^{(10)}$ and ex vivo ${ }^{(34)}$ experiments, we have used identical concentrations of cholesterol and plant stanols/sterols to evaluate their impact on the changes in the behaviour of T-cells. These studies have suggested that effects are plant stanol and sterol specific. However, further studies are needed to examine whether these effects can be extrapolated to the results of the present study.

In summary, an acute intake of plant stanol esters did not change the expression profiles of genes involved in sterol metabolism $5 \mathrm{~h}$ postprandially. However, the pathways 
involved in T-cell functions were consistently down-regulated in the jejunum. The physiological and functional consequences of plant stanol ester-induced immunomodulatory effects deserve further investigation.

\section{Supplementary material}

To view supplementary material for this article, please visit http://dx.doi.org/10.1017/S000711451400350X

\section{Acknowledgements}

The authors thank all the study participants for their time and effort. They also thank Maud Beckers and Maurice Konings for their technical support and our dietitian, Nina Wystyrk, for nutritional counselling throughout the study. The authors thank Elhaseen Elamin, Nico Kloosterboer and Melanie Schnijderberg for the immunohistochemical analysis.

The present study was financially supported by Raisio Life Sciences, Finland. Raisio had no role in the design or analysis of the study, or in the writing of this article.

The authors' contributions are as follows: E. D. S., R. P. M. and J. P. designed the research; E. D. S. conducted the research; R. d. R. was responsible for collecting the biopsy samples; E. D. S., R. P. M. M. V. B. and J. P. analysed the data; E. D. S., R. P. M., M. V. B., T. G. A. M. W., W. T. V. G. R. d. R. and J. P. wrote the paper; J. P. had primary responsibility for the final content. All authors read and approved the final manuscript.

The authors have no conflict of interest to declare.

\section{References}

1. Ling WH \& Jones PJ (1995) Dietary phytosterols: a review of metabolism, benefits and side effects. Life Sci 57, 195-206.

2. Racette SB, Lin X, Lefevre M, et al. (2010) Dose effects of dietary phytosterols on cholesterol metabolism: a controlled feeding study. Am J Clin Nutr 91, 32-38.

3. Plat J, Mackay D, Baumgartner S, et al. (2012) Progress and prospective of plant sterol and plant stanol research: report of the Maastricht meeting. Atherosclerosis 225, 521-533.

4. De Smet E, Mensink RP \& Plat J (2012) Effects of plant sterols and stanols on intestinal cholesterol metabolism: suggested mechanisms from past to present. Mol Nutr Food Res 56, $1058-1072$.

5. Lee IA, Kim EJ \& Kim DH (2012) Inhibitory effect of $\beta$-sitosterol on TNBS-induced colitis in mice. Planta Med 78, 896-898.

6. Baskar AA, Ignacimuthu S, Paulraj GM, et al. (2010) Chemopreventive potential of $\beta$-sitosterol in experimental colon cancer model - an in vitro and in vivo study. BMC Complement Altern Med 10, 24.

7. Brufau G, Kuipers F, Lin Y, et al. (2011) A reappraisal of the mechanism by which plant sterols promote neutral sterol loss in mice. PLOS ONE 6, e21576.

8. Field FJ, Born E \& Mathur SN (1997) Effect of micellar $\beta$-sitosterol on cholesterol metabolism in $\mathrm{CaCo}-2$ cells. J Lipid Res 38, 348-360.

9. Plat J \& Mensink RP (2002) Increased intestinal $A B C A 1$ expression contributes to the decrease in cholesterol absorption after plant stanol consumption. FASEB J 16, 1248-1253.
10. Brüll F, Mensink RP, Steinbusch MF, et al. (2012) Beneficial effects of sitostanol on the attenuated immune function in asthma patients: results of an in vitro approach. PLOS ONE 7, e46895.

11. Gylling H, Puska P, Vartiainen E, et al. (1999) Serum sterols during stanol ester feeding in a mildly hypercholesterolemic population. J Lipid Res 40, 593-600.

12. Mensink RP, Ebbing S, Lindhout M, et al. (2002) Effects of plant stanol esters supplied in low-fat yoghurt on serum lipids and lipoproteins, non-cholesterol sterols and fat soluble antioxidant concentrations. Atherosclerosis 160, 205-213.

13. Wolfs TG, Buurman WA, Zoer B, et al. (2009) Endotoxin induced chorioamnionitis prevents intestinal development during gestation in fetal sheep. PLOS ONE 4, e5837.

14. Chen Q, Gruber H, Pakenham C, et al. (2009) Dietary phytosterols and phytostanols alter the expression of sterol-regulatory genes in SHRSP and WKY inbred rats. Ann Nutr Metab 55, 341-350.

15. Scoggan KA, Gruber H, Chen Q, et al. (2009) Increased incorporation of dietary plant sterols and cholesterol correlates with decreased expression of hepatic and intestinal $A b c g 5$ and $A b c g 8$ in diabetic BB rats. J Nutr Biochem 20, 177-186.

16. Tachibana S, Hirano M, Hirata T, et al. (2007) Cholesterol and plant sterol efflux from cultured intestinal epithelial cells is mediated by ATP-binding cassette transporters. Biosci Biotechnol Biochem 71, 1886-1895.

17. Plat J, Bragt MC \& Mensink RP (2005) Common sequence variations in ABCG8 are related to plant sterol metabolism in healthy volunteers. J Lipid Res 46, 68-75.

18. Dieter MZ, Maher JM, Cheng X, et al. (2004) Expression and regulation of the sterol half-transporter genes $A B C G 5$ and ABCG8 in rats. Comp Biochem Physiol C Toxicol Pharmacol 139, 209-218.

19. Kang CK \& Lee TH (2014) Medaka villin 1-like protein (VILL) is associated with the formation of microvilli induced by decreasing salinities in the absorptive ionocytes. Front Zool 11, 2.

20. Igel M, Giesa U, Lutjohann D, et al. (2003) Comparison of the intestinal uptake of cholesterol, plant sterols, and stanols in mice. J Lipid Res 44, 533-538.

21. Repa JJ, Berge KE, Pomajzl C, et al. (2002) Regulation of ATP-binding cassette sterol transporters ABCG5 and ABCG8 by the liver X receptors $\alpha$ and $\beta$. J Biol Chem 277, 18793-18800.

22. Davis HR Jr, Zhu LJ, Hoos LM, et al. (2004) Niemann-Pick C1 Like 1 (NPC1L1) is the intestinal phytosterol and cholesterol transporter and a key modulator of whole-body cholesterol homeostasis. J Biol Chem 279, 33586-33592.

23. Repa JJ, Dietschy JM \& Turley SD (2002) Inhibition of cholesterol absorption by SCH 58053 in the mouse is not mediated via changes in the expression of mRNA for ABCA1, ABCG5, or ABCG8 in the enterocyte. I Lipid Res 43, 1864-1874.

24. Sanders TA, Filippou A, Berry SE, et al. (2011) Palmitic acid in the sn-2 position of triacylglycerols acutely influences postprandial lipid metabolism. Am J Clin Nutr 94, 1433-1441.

25. Kaneko E, Matsuda M, Yamada Y, et al. (2003) Induction of intestinal ATP-binding cassette transporters by a phytosterolderived liver $\mathrm{X}$ receptor agonist. $J$ Biol Chem 278, 36091-36098.

26. Lally S, Tan CY, Owens D, et al. (2006) Messenger RNA levels of genes involved in dysregulation of postprandial lipoproteins in type 2 diabetes: the role of Niemann-Pick 
C1-like 1, ATP-binding cassette, transporters G5 and G8, and of microsomal triglyceride transfer protein. Diabetologia $\mathbf{4 9}$ 1008-1016.

27. Phillips C, Mullan K, Owens D, et al. (2006) Intestinal microsomal triglyceride transfer protein in type 2 diabetic and non-diabetic subjects: the relationship to triglyceriderich postprandial lipoprotein composition. Atherosclerosis $\mathbf{1 8 7}, 57-64$

28. Calpe-Berdiel L, Escola-Gil JC, Benitez S, et al. (2007) Dietary phytosterols modulate T-helper immune response but do not induce apparent anti-inflammatory effects in a mouse model of acute, aseptic inflammation. Life Sci $\mathbf{8 0}$, 1951-1956.

29. Mosmann TR \& Coffman RL (1989) TH1 and TH2 cells: different patterns of lymphokine secretion lead to different functional properties. Annu Rev Immunol 7, 145-173.
30. Koboziev I, Reinoso Webb C, Furr KL, et al. (2013) Role of the enteric microbiota in intestinal homeostasis and inflammation. Free Radic Biol Med 68, 122-133.

31. Martinez I, Perdicaro DJ, Brown AW, et al. (2013) Diet-induced alterations of host cholesterol metabolism are likely to affect the gut microbiota composition in hamsters. Appl Environ Microbiol 79, 516-524.

32. Bensinger SJ, Bradley MN, Joseph SB, et al. (2008) LXR signaling couples sterol metabolism to proliferation in the acquired immune response. Cell 134, 97-111.

33. Glass CK \& Saijo K (2008) Immunology: oxysterols hold $\mathrm{T}$ cells in check. Nature 455, 40-41.

34. Brull F, Mensink RP, van den Hurk K, et al. (2010) TLR2 activation is essential to induce a Th1 shift in human peripheral blood mononuclear cells by plant stanols and plant sterols. J Biol Chem 285, 2951-2958. 